\title{
Research on the Application of WeChat Public Platform in Mobile Learning

\author{
Ying Luo ${ }^{1,}$ a, $\mathrm{HaO} \mathrm{Lu}^{2, \mathrm{~b}}$
} \\ ${ }^{1}$ Education School, Jiangxi Science \& Technology Normal University, Nanchang, China \\ ${ }^{2}$ Jiangxi Vocational \& Technical College of Information Application, Nanchang, China \\ amooonly@126.com; b309981413@qq.com
}

Keywords: WeChat; public platform; mobile learning

\begin{abstract}
With the rapid development of information and mobile internet technology and the popularity of mobile devices, mobile learning has received unprecedented attention. At the same time, the number of WeChat users break 200 million in six mouths, providing new inspiration for our education. Mobile learning based on WeChat public platform breaks the restriction of time and space in the traditional teaching and creates the omnipresent pervasive learning environment for students. Starting from the characteristics and advantages of WetChat public platform, the paper analyzes the specific application of WetChat public platform in mobile learning, and discusses the issues existing, in order to put forwards new ideas for the further application.
\end{abstract}

\section{Introduction}

With the rapid development of information and mobile internet technology and the popularity of mobile devices, mobile learning has received unprecedented attention. WeChat, as a mobile instant messaging software launched in 2012 by Tencent Company, has been welcomed by users immediately since launched. According to the third party statistics, as of the fourth quarter of 2014, the number of WeChat users had reached 730 million. College students are the important group of WeChat application, therefore, WeChat provides new research application platform for mobile learning.

\section{The induction of WeChat public platform}

WeChat public platform is the new function module added on August, 2012 by Tencent Company on the basis of WeChat. The enterprises and users can build their own WeChat public number on the basis of the platform, and then provide more comprehensive services for users through pushing text, pictures, voice and music, setting the automatic reply, etc.

As a new type of media, it has the following characteristics: first, micro. The information contents pushed can be a picture, a small video, a segment of speech. Second, it processes a very wide range of user groups. According to report released by Tencent, as of the first quarter of 2015, the WeChat users has reached 549 million monthly, covering more than $90 \%$ of smart phones. Third, operating cost is low and the operation is simple. Users do not need additional technical and cost. They only need to login the platform and finish registration to get one public account, and then manage their own platform and sent the information to the people paying attention to the corresponding number. Fourth, the rate of information push is high. Users only need to install the WeChat client on the mobile terminal device and achieve interaction of the information with the administrator through the network platform. Fifth, the form of the content pushing is various. Through WeChat public platform, the learners can not only achieve the rapid transmission of text, but also pictures, voice and video. 


\section{The induction of mobile learning}

The concept of mobile learning was first introduced into China in 2000 by Desmond. It is a kind of learning that can be carried out at any time and place with the help of mobile computing devices (smart phones, I Pad, laptops).

It has the following characteristics. First, learning pattern is mobile. With the development of internet technology, mobile learning is no longer affected by the constraint of traditional teaching space, and the teaching scene can be cinemas, buses, subway stations, etc. second, autonomy of learning demand. In the process of mobile learning, learners can arrange their own study scene, learning time and learning contents, and download the teaching resources. Third, learning time fragmentation. Due to the mobility and complexity of the mobile learning scene, the learners are very difficult to guarantee the concentration of attention and the learning process is easy to be interrupted. Therefore, the learners can only reorganize the fragmented time. Fourth, learning resources are minimized. Generally speaking, the time of mobile learning is not fixed, which determines the mobile learning resources show the characteristic of miniaturization. Otherwise, the learners will interrupt the learning because of dull and boring learning resources.

\section{The advantage of the application of WeChat public platform in mobile learning}

WeChat public platform combines limited classroom learning time with infinite after-class time, and integrates ability training objectives with course teaching goal, to achieve seamless connection between study in and after class. Making full use of WeChat public platform can develop the integrated learning inside and outside the classroom, and cultivate students' learning habits.

The broadest learning environment. The students can access to learning resources at any time and any place they want through wireless mobile devices (such as mobile terminal, handheld computer and mobile phone with wireless communication module, etc), and communicate with others. The learning style can provide students whenever and wherever learning due to the characteristics of flexibility, convenience and non linear. WeChat public platform can create ubiquitous learning environment for students.

The highest information arrival rate. Though mobile phone and other terminals, WeChat public platform can browse the information and sent message at anytime and anywhere to take full use of fragmented time. WeChat public platform is one to more communication and realizes all-round interaction with certain text, pictures and voice of specific groups to sent message to mobile phone directly. Therefore, the arrival rate and the viewing rate is almost $100 \%$.

Maximized free option. WeChat public platform can give students more freedom through putting the process of knowledge outside the classroom to let them choose the most ideal time and the most suitable way to accept new knowledge while the process of knowledge internalization in the classroom to have more communication and exchange with students and teachers.

\section{The specific application of WeChat public platform in mobile learning}

Push the information through the mass function to provide learners with the support of mobile learning. Background managers can make text, audio, video and other information suitable for mobile learning into various micro courses according to a certain teaching design, and then push to the learners through the WeChat public platform. The learners paid attention to the account can make full of their fragmented learning time to learn what they want to know at any time. At the same time, the mangers can also add the web link of "read the full text on the push public platform to recommend the contents of the article to learners to enrich their learning point.

Reply the content by setting key words to mobilize the learners' learning initiative. The administrator blind the materials done well before through using the function of setting key words in the background, and then the learners can find the knowledge they need accurately by replying to the corresponding keywords according to the keywords input prompts. This way of automatic reply increase their learning interest and arouse their initiative. 
Query the learners' message and answer question by one to one. Through the real-time message capability of the platform, the administrator can browse the message regularly on the platform and answer their questions pertinently. The answer mode of one to one ensure the confidentiality of the dialogue between the learner and the administrator and avoid the embarrassment of asking simple questions in tradition classroom. The administrator can find the defects of learning content according to the learners' problem, so as to adjust the content immediately.

Teach students in accordance with their aptitude and push personalized courses. At the beginning, the administrator groups the fans of the platform according to the gender or the area through the background of user management, and then pushes specific courses pertinently to the learner grouped. At later stage, analyze the learners' study status according to their learning feedback (test scores and learning message), and then push different learning contents according to different learning level after grouped again.

Provide sharing function to facilitate the formation of learning community. The public account promotes the practical content suitable for social sharing to learners and adds the sharing button in the upper right corner of the picture and text. The learners can send the content to their own social network while viewing the message. In addition, they can also initiate the topic through the group chat function and discuss and share their own learning experience, in order to achieve common progress.

\section{The problems of WeChat public platform in mobile learning}

The function of WeChat public platform doesn't be maximized the use. most of the WeChat public platform focus on the use of its communication function to realize the information interaction between teachers and students, but don't use the open interface function to line two development to integrate the existing network teaching resources, and bring into teaching process control and evaluation outcomes to change the function of the traditional teaching model.

The interaction between the users and the platform is lagging. Although point-to-point exchange can be carried out through WeChat public platform, the administrator can not understand how many people have read the information every day and the learners can only view the information pushed. So the learner can not ask their questions directly and have to leave message, which leads to the lag of communication between the users and the platform.

The trend for interests of WeChat public platform is obvious. Undeniably, the vast majority of educational institutions are to gain profits to build the WeChat public platform. The real free and public welfare WeChat public platform is very small, except some institutions. As the education institution of businesses, they consider the platform as propaganda marketing tool more than mobile learning platform. They always pay attention to pushing a lot of advertising information while providing less learning information.

\section{Summary}

WeChat public platform can integrate with education resources effectively and become an important mobile learning platform for the majority of users. Therefore, we must keep up with the pace of the times to update ideas and strengthen understanding.

\section{References}

[1] Hao Bai, Jingjing Hao. The research on the application of WetChat public platform in High Education[J]. Chinese Education Information, 2013(4):78-81.

[2] Fanli Meng, Lin Chen. The research on the construction of mobile learning space base on WetChat public platform[J]. Modern Education Technology, 2014(10).

[3] Ping Wang. The analysis of the support function and design principles of WeChat mobile learning[J]. Journal of Distance Education, 2013(6). 
[4] Shifa Lu, Yonggang Du. Thinking and practice of mobile learning based on WetChat public platform[J]. Tianjin University press, 2015(2).

[5] Huafeng Guo, Chengcai Mei. The design of micro-class mobile learning platform based on WetChat public platform[J]. Chinese Education Information, 2015(1):82-84.

[6] Theo Hug. Micro learning: A New Pedagogical Challenge (Introductory Note) [C]// Micro Learning Conference2005. Australia, Innsbruck: Innsbruck University Press.2006:7-12.

[7] Martin Lindner, Peter A.Bruck. Micromedia and Corporate Learning: Proceedings of the 3rd International Mi-crolearning2007Conference [M]. Innsbruck: Innsbruck University Press, 2007(8). 